\title{
CoNiCr 合金熱処理メディアの熱処理条件に関する検討
}

\author{
A Study of Heat Treatment Conditions for CoNiCr Alloy Heat-Treated Media
}

\author{
佐藤元治 \\ （株）神戸製銅所 技術開発本部電子技術研究所，兵庫県神戸市西区高塚台 1-5-5（-651-22） \\ M. Sato
}

Electronics Research Laboratory, Technical Development Group, Kobe Steel, Ltd., 5-5, Takatsukadai 1-chome, Nishi-ku, Kobe, Hyogo 651-22

\begin{abstract}
The effect of heat treatment conditions on the magnetic properties of $\mathrm{Zr} / \mathrm{CoNiCr}$ alloy/Cr heat-treated media was investigated. When the heating rate, holding time, and cooling rate were $220^{\circ} \mathrm{C} / \mathrm{min}, 1 \mathrm{~s}$, and $1000^{\circ} \mathrm{C} / \mathrm{min}$, respectively, the same magnetic properties were obtained as in the standard conditions, that is, a heating rate of $90^{\circ} \mathrm{C} / \mathrm{min}$, a holding time of $60 \mathrm{~s}$, and a cooling rate of $13^{\circ} \mathrm{C} / \mathrm{min}$. From the results of XPS analysis, it was found that $\mathrm{Cr}$ diffused from the $\mathrm{Cr}$ underlayer into the $\mathrm{CoNiCr}$ alloy layer with increasing heat treatment temperature, as in the standard conditions. Therefore, it is considered that an increase in $H_{\mathrm{c}}$ with increasing heat treatment temperature caused the $\mathrm{Cr}$ to be segregated from the $\mathrm{Cr}$ underlayer into the grain boundaries of the CoNiCr alloy, as in the standard conditions.
\end{abstract}

Key words: heat-treated media, heat treatment condition, high coercivity, low noise, $\mathrm{CoNiCr}$ alloy, heating rate, holding time, cooling rate, carbon substrate, other substrate

\section{1. まえがき}

磁気ディスク（メディア）の面記録密度の向上により，磁気 ディスク装置の小型・大容量化が進行している゙．面記録密度 の増加は, 高保磁力・低ノイズな媒体の採用による線記録密度 の向上および MR ヘッドの採用によるトラック密度の向上に より図られている.

我々は,これまでに耐熱性に優れたカーボン基板2゙を用いて， 保茫膜として一般に用いられる $\mathrm{C}^{3)}$ に代わり，Zr 保讙膜 /Co 基合金磁性膜 / $\mathrm{Cr}$ 下地膜構造を有する磁気ディスクを作製し, その後に熱処理を施すことにより，Co 基合金結晶粒界への $\mathrm{Cr}$ の偏析を促進させ, 保磁力 $\left(H_{\mathrm{c}}\right)$ を大幅に增大できること市およ び, 低ノイズ化が可能なことら)を報告した。この際, 熱処理条件 として, 舁温速度 $=90^{\circ} \mathrm{C} / \mathrm{min}$, 保持時間 $=60 \mathrm{~s}$, および降温速 度 $=13^{\circ} \mathrm{C} / \mathrm{min}$ を採用した（以下，標準作製条件と記す）。この ため，熱処理条件が熱処理メディアの磁気特性に及ぼす影蔀に ついては,これまで詳細に調查されていなかった。

そこで，本論文では，熱処理条件が磁気特性に及ぼす影整を 調查することを目的に，熱処理時の昇温速度，保持時間，およ び降温速度と熱好理メディアの磁気特性の関係について調査し たので，その結果を報告する。

\section{2. 实臤方法}

本実験では，これまでと同様に HIP 処理した後に表面研磨 を施した 2.5 インチタイプのカーボン基板 2 を用いた. インラ インタイプの DC マグネトロンスパッタ装置により，Ar压力 $3 \mathrm{mT}$ orr, 基板加熱時の設定温度 $300^{\circ} \mathrm{C}$ にて, $\mathrm{Cr}, \mathrm{Co}_{62.5}$ $\mathrm{Ni}_{30} \mathrm{Cr}_{7.5}$ 合金, および $\mathrm{Zr}$ ターゲットを用いて，各層， $3000 \AA$, $400 \AA$ ，および $300 \AA$ の膜厚 $(\delta)$ で順に成膜した. また， $8 \times 8$ $\mathrm{mm}$ 角に切断したものを熱好理用試料とした．熱処理前の磁気 特性は膜面内での磁堨印加方向に関係なく， $H_{\mathrm{c}}$ は $1150 \mathrm{Oe}$ 一

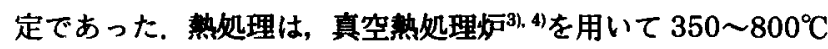
の範囲で行った.この际，Fig. 1 に示す熱処理パターンにより， 昇温速度 $=14 \sim 220^{\circ} \mathrm{C} / \mathrm{min}$, 保持時間 $=1 \sim 1800 \mathrm{~s}$, 降温速度 $=13 \sim 1000^{\circ} \mathrm{C} / \mathrm{min}$ とし, 真空度は $30 \mathrm{mTorr}$ 一定とした. 磁 気特性は, 振動試料型磁力計 (VSM) に上り, 膜面に平行に最大 $10 \mathrm{kOe}$ まで磁場を田加し，熱好理前後について測定した。さ らに, $\mathrm{Mg}-K_{a}$ 線を X 線源とする X 線光電子分光装置 (XPS) に より，各条件で作製した熱処理メディアについて深さ方向の組 成分布を測定した。

\section{3. 实的結果およひ考家}

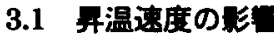

熱処理温度 $=550^{\circ} \mathrm{C}$, 保持時間 $=60 \mathrm{~s}$, 降温速度 $=13^{\circ} \mathrm{C} / \mathrm{min}$ 一定とし，昇温速度を变化して熱処理メディアを作製した，昇 温速度と熱処理前後での $H_{\mathrm{c}}$ の変化を Fig. 2 に示す. $14^{\circ} \mathrm{C} /$ $\min$ から $220^{\circ} \mathrm{C} / \min$ の間においては, 熱処理後の $H_{\mathrm{c}}$ に変化

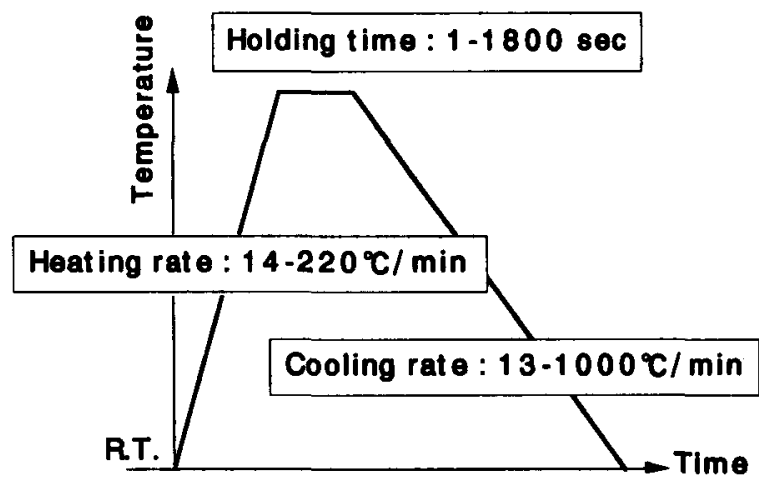

Fig. 1 Heat treatment pattern. 


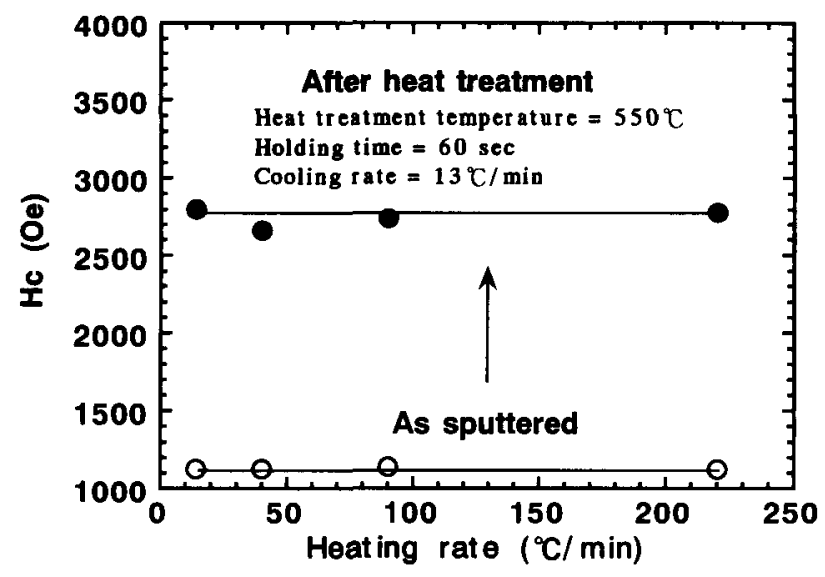

Fig. 2 Relation between the heating rate and $H_{c}$.

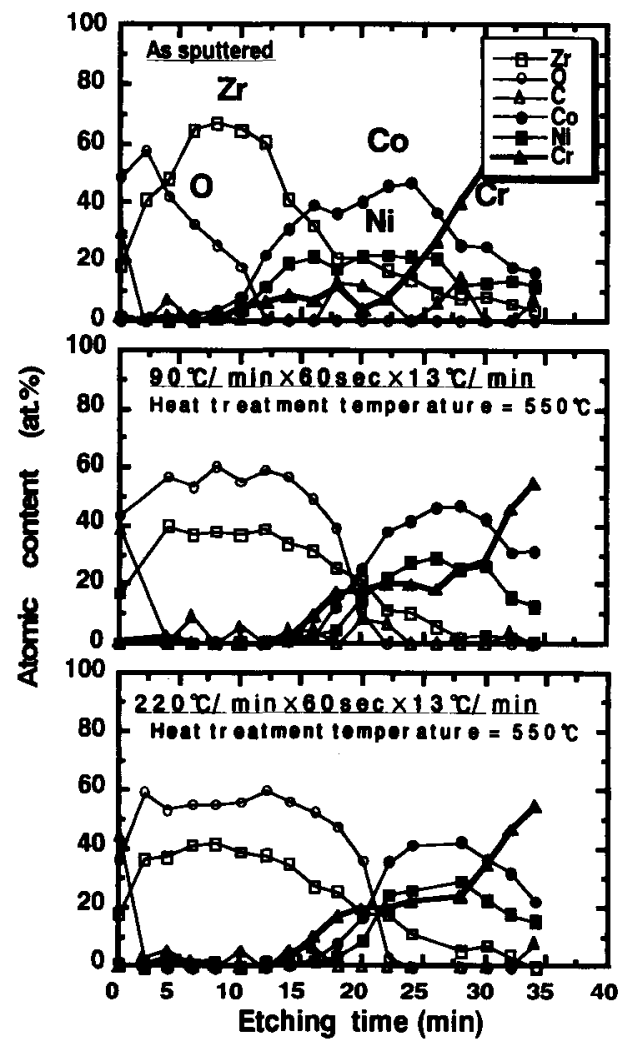

Fig. 3 Relation between the etching time and the atomic content.

は見られない. また，他の磁気特性 $\left(B, S, S^{*}\right)$ も同様であった。 標準作製条件である昇温速度が $90^{\circ} \mathrm{C} / \mathrm{min}$ および $220^{\circ} \mathrm{C} / \mathrm{min}$ の場合の深さ方向での組成分布を成膜後の場合とともに Fig. 3 に示す，標準作製条件の場合には，すでに報告したように文, $\mathrm{Cr}$ 下地膜から Cr が拡散し， CoNiCr 合金結晶粒界へ偏析するこ とにより $H_{\mathrm{c}}$ が向上している. また, 昇温速度が $220^{\circ} \mathrm{C} / \mathrm{min} の$ 場合にも，Cr下地膜から CoNiCr 合金膜中への $\mathrm{Cr}$ の拡散が見 られることから，標準作製条件と同様なメカニズムにより $H_{\mathrm{c}}$ が向上しているすのと考えられる。

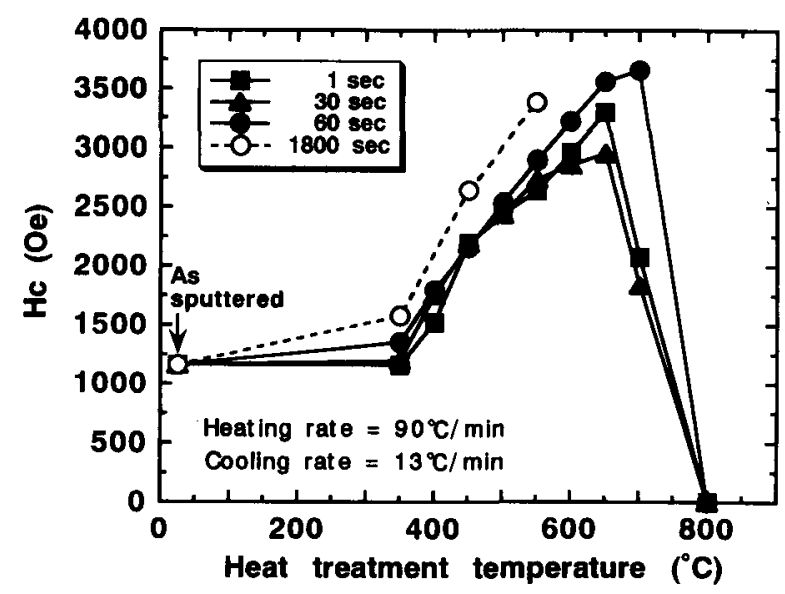

Fig. 4 Relation between the heat treatment temperature and $H_{\mathrm{c}}$.

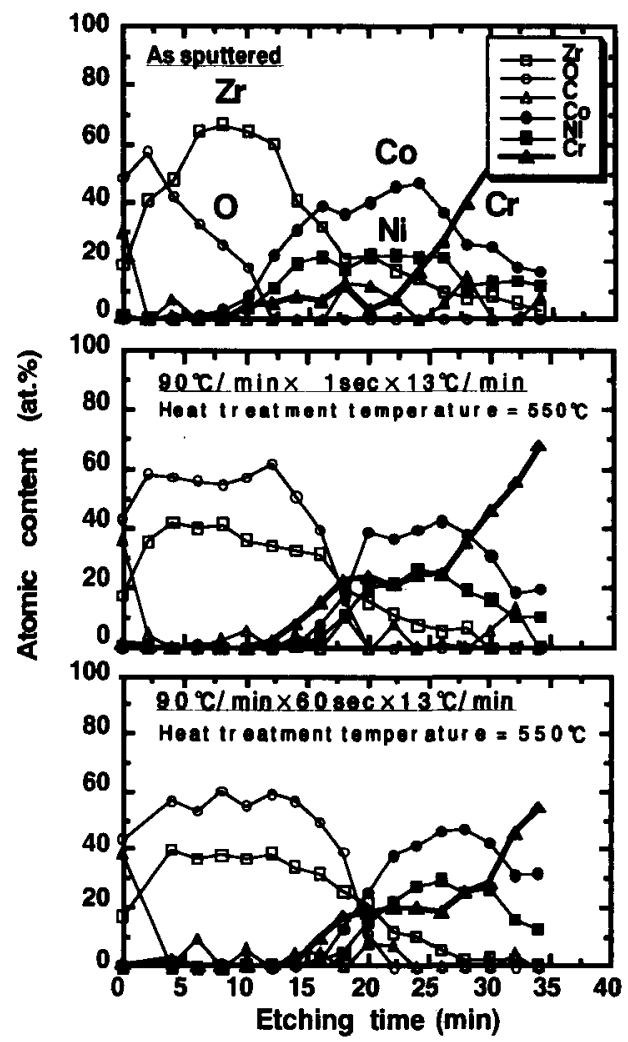

Fig. 5 Relation between the etching time and the atomic content.

\section{2 保持時间の影望}

保持時間の影響を調查するため，昇温速度 $=90^{\circ} \mathrm{C} / \mathrm{min}$, 降 温速度 $=13^{\circ} \mathrm{C} / \mathrm{min}$ 一定として熱処理温度および保持時間を変 化し熱処理メディアを作製した．Fig. 4 K，保持時間が 1 1800 秒間での熱処理後の $H_{\mathrm{c}}$ の測定結果を示す. 1800 秒間と 保持時間が非常に長時間の場合には, 60 秒間以内の短時間の 場合の $H_{\mathrm{c}}$ の変化とは異なった㑯向を示している.Fig. 5 には, 保持時間が 1 秒間および標準作製条件である 60 秒間の場合に ついて測定した，樑さ方向の組成分布を成膜後の場合とともに

日本応用磁気学会誌 Vol. 19, No. 2, 1995 
示す. $\mathrm{CoNiCr}$ 合金膜中への $\mathrm{Cr}$ の拡散度合いは, ある温度以上 では温度と時間の積で決定されるものと考えられるが, 昇温速 度を変化した場合と同様に，60 秒間以内での熱処理では保持 時間によらず同様な組成分布を示している。これは， $H_{\mathrm{c}}$ の変 化,つまりは，Cr の拡散による粒界偏析の割合が 60 秒間以内 では保持時間によらず熱処理温度のみで決定されていることを 示しているものと考えられる. なお，1800 秒間での熱処理で は, $\mathrm{Cr}$ 下地膜加らの Cr の拡散量, つまりは, $\mathrm{CoNiCr}$ 合金結晶 粒界への Cr の偏析割合が多くなり, 同一 $H_{\mathrm{c}}$ を得るための熱処 理温度が低温側ヘシフトしたものと考えられる。

\section{3 降温時间の影策}

これまでの結果を元に, 昇温速度 $=220^{\circ} \mathrm{C} / \mathrm{min}$, 保持時間 $=$ $1 \mathrm{~s}$, 降温速度を $1000^{\circ} \mathrm{C} / \mathrm{min}$ として, 熱処理温度を変化し熱処 理メディアを作製した。熱処理後の $H_{\mathrm{c}}$ の測定結果を Fig. 6 に 示す. 図中には, 標準作製条件で作製した熱処理メディアの $H_{\mathrm{c}}$ の変化も併せて示す. 昇温速度 $=220^{\circ} \mathrm{C} / \mathrm{min}$, 保持時間 $=1 \mathrm{~s}$, 降温速度が $1000^{\circ} \mathrm{C} / \mathrm{min}$ と非常に短時間の場合にも標準作製 条件と同様な $H_{\mathrm{c}}$ の変化が得られており, 今回の条件の範囲内 では， $H_{\mathrm{c}}$ の変化が降温速度にも関係していないことを示して いる. また, Fig. 7 には, 上記試料での $B_{\mathrm{r}} \delta$ と $H_{\mathrm{c}}$ の関係を, さ らに, Fig. 8 には, 熱処理温度と $S^{*}$ との関係を示す. 降温速度 によらず, $B_{\mathrm{r}} \delta$ と $H_{\mathrm{c}}$ の関係は同様な変化を示しており，また， $S^{*}$ む $H_{\mathrm{c}}$ の增加ととむに減少していることから, 熱処理温度の 増加による $\mathrm{CoNiCr}$ 合金結晶粒の磁気的分離度の増加が考えら れる5).このことから, 非常に短時間での処理でも， $\mathrm{Cr}$ 下地膜 から CoNiCr 合金膜中への Cr の拡散により, CoNiCr 合金結 晶粒界への Cr の偏析が同様な割合で生じているむのと推定さ れる.

以上から, $\mathrm{Cr}$ の拡散に伴う磁気特性の変化は, 今回検討した 条件の範囲内（ただし，保持時間 1800 秒間は除く）では昇温 速度, 保持時間, おょび降温速度には関係なく, 熱処理温度の みが関与していることが明らかとなった。このことは，媒体の みを瞬間的に加熱することにより磁気特性の改善が可能になる ことを意味しており，カーボン基板以外の耐熱性を有しない基 板が使用できる可能性が得られたものと考えられる.

\section{4.むす ひ}

. $\mathrm{Zr} / \mathrm{CoNiCr}$ 合金/ $\mathrm{Cr}$ 構造の熱処理メディアについて熱処理 時の昇温速度, 保持時間，および降温速度が磁気特性に及ぼす 影響を調查した結果，以下のことが明らかとなった。

(1) 昇温速度 $=220^{\circ} \mathrm{C} / \mathrm{min}$, 保持時間 $=1 \mathrm{~s}$, 降温速度 $=$ $1000^{\circ} \mathrm{C} / \mathrm{min}$ の超短時間処理であ従来（昇温速度 $=90^{\circ} \mathrm{C} / \mathrm{min}$, 保持時間 $=60 \mathrm{~s}$, 降温速度 $=13^{\circ} \mathrm{C} / \mathrm{min}$ ) 之同様な磁気特性が得 られた。

(2) XPS 分析の結果,このような条件下での磁気特性の改 善む, 従来之同様に $\mathrm{Cr}$ が $\mathrm{CoNiCr}$ 合金膜中へ拡散することに より,つまりは, CoNiCr 合金結晶粒界への Cr の偏析によるも のであることが明らかとなった。

（3）なお，今回の条件内では， $H_{\mathrm{c}}$ の増大には熱処理温度のみ 日本応用磁気学会誌 Vol. 19, No. 2, 1995

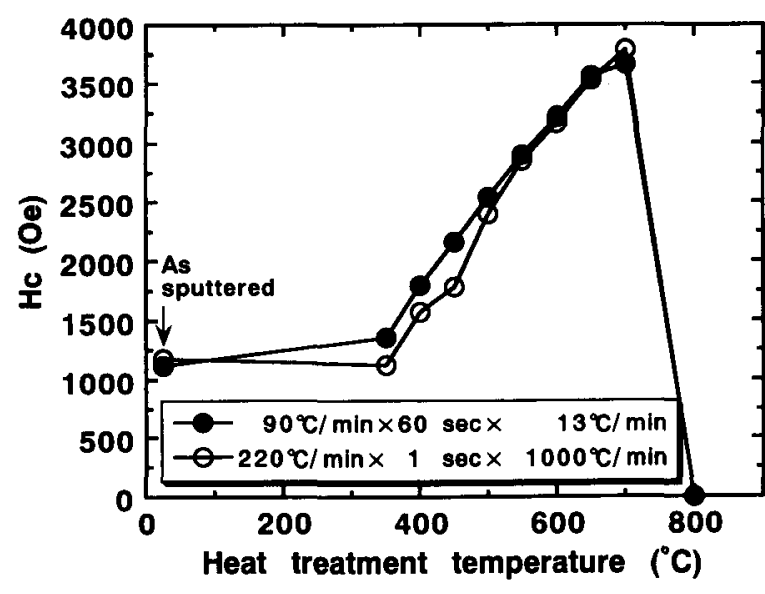

Fig. 6 Relation between the heat treatment temperature and $H_{\mathrm{c}}$.

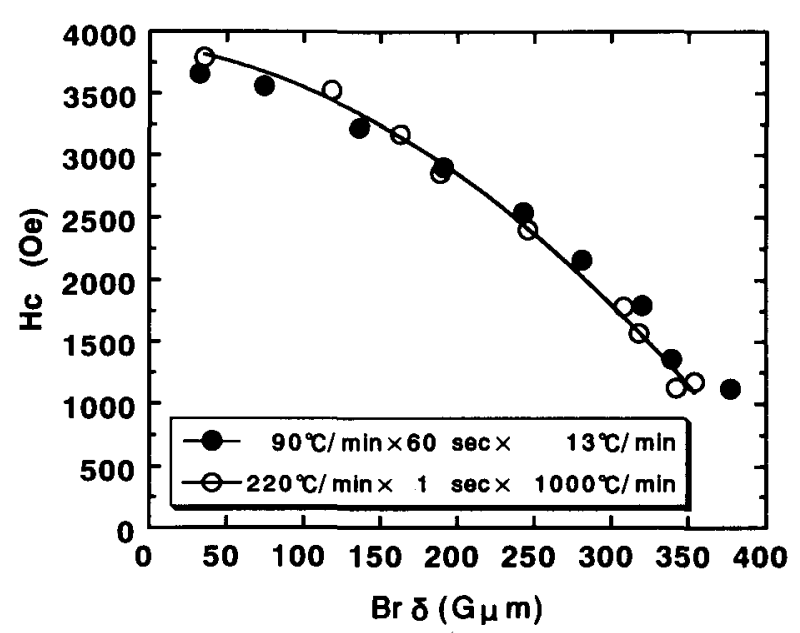

Fig. 7 Relation between $B_{r} \delta$ and $H_{\mathrm{c}}$.

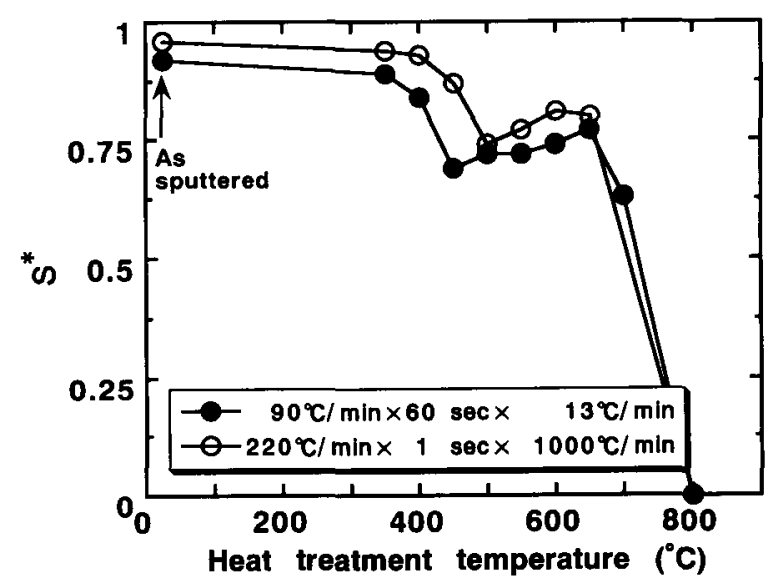

Fig. 8 Relation between the heat treatment temperature and $S^{*}$.

が関与していることが明らかとなった。したがって，媒体のみ を瞬間的に加熱することにより磁気特性の改善が可能になるも のと考えられ，カーボン基板以外の耐熱性を有しない基板が使 用できる可能性が得られた。 
群 本研究を進めるに当たり，成膜および評洒に協力頂 いた，当社，開発業務部試作実験室の林 菊三郎氏に感謝致し ます。

\section{文献}

1) E. S. Murdock, R. F. Simmons, and R. Davidson: IEEE Trans. Magn., 28, 3078 (1992).
2）佐藤元治，大西良彦，中上明光：日本応用整気学会誌，17，101 (1993).

3）佐藤元治，大西良彦，林 秀高：信学論 (C-II), J76-C-II, 601 (1993).

4) M. Sato, Y. Onishi, and A. Nakaue: IEEE Trans. Magn., 29, 3685 (1993).

5) 佐藤元治, 中上明光：日本応用磁気学会誌，18，85 (1994). 1994 年 10 月 12 日受理, 1995 年 1 月 20 日探錄 